\title{
Role of N-Type Voltage-Dependent Calcium Channels in Autoimmune Optic Neuritis
}

\author{
Ivana Gadjanski, PhD, ${ }^{1,2}$ Susann Boretius, $\mathrm{PhD},{ }^{3}$ Sarah K. Williams, $\mathrm{PhD},{ }^{4}$ Paul Lingor, MD, ${ }^{1,5}$ \\ Johanna Knöferle, MD, ${ }^{1}$ Muriel B. Sättler, MD,${ }^{1}$ Richard Fairless, PhD, ${ }^{4}$ Sonja Hochmeister, MD, PhD, ${ }^{6}$ \\ Kurt-Wolfram Sühs, MD, ${ }^{4}$ Thomas Michaelis, PhD, ${ }^{3}$ Jens Frahm, PhD, ${ }^{3}$ Maria K. Storch, MD, ${ }^{6}$ \\ Mathias Bähr, MD, ${ }^{1,5}$ and Ricarda Diem, $\mathrm{MD}^{4}$
}

\begin{abstract}
Objective: The aim of this study was to investigate the role of voltage-dependent calcium channels (VDCCs) in axon degeneration during autoimmune optic neuritis.

Methods: Calcium ion $\left(\mathrm{Ca}^{2+}\right)$ influx into the optic nerve $(\mathrm{ON})$ through VDCCs was investigated in a rat model of optic neuritis using manganese-enhanced magnetic resonance imaging and in vivo calcium imaging. After having identified the most relevant channel subtype (N-type VDCCs), we correlated immunohistochemistry of channel expression with ON histopathology. In the confirmatory part of this work, we performed a treatment study using $\omega$-conotoxin GVIA, an N-type specific blocker. Results: We observed that pathological $\mathrm{Ca}^{2+}$ influx into ONs during optic neuritis is mediated via N-type VDCCs. By analyzing the expression of VDCCs in the inflamed ONs, we detected an upregulation of $\alpha_{1 \mathrm{~B}}$, the pore-forming subunit of $\mathrm{N}$-type VDCCs, in demyelinated axons. However, high expression levels were also found on macrophages/activated microglia, and lower levels were detected on astrocytes. The relevance of N-type VDCCs for inflammation-induced axonal degeneration and the severity of optic neuritis was corroborated by treatment with $\omega$-conotoxin GVIA. This blocker led to decreased axon and myelin degeneration in the ONs together with a reduced number of macrophages/activated microglia. These protective effects were confirmed by analyzing the spinal cords of the same animals.

Interpretation: We conclude that N-type VDCCs play an important role in inflammation-induced axon degeneration via two mechanisms: First, they directly mediate toxic $\mathrm{Ca}^{2+}$ influx into the axons; and second, they contribute to macrophage/microglia function, thereby promoting secondary axonal damage.
\end{abstract}

Ann Neurol 2009;66:81-93

Multiple sclerosis (MS) is an inflammatory, demyelinating disease of the central nervous system, accompanied by neurodegeneration that determines chronic disability. ${ }^{1,2}$ Studies in humans and animal models ${ }^{3-8}$ have shown that axonal and neuronal damage starts during early disease stages. One of the most common clinical manifestations of MS is optic neuritis. ${ }^{\text {? }}$

Experimental autoimmune encephalomyelitis (EAE) is the principal model of MS. ${ }^{10}$ We have previously demonstrated that myelin oligodendrocyte glycoprotein-induced EAE in brown Norway rats leads to optic neuritis in 80 to $90 \%$ of animals with consecutive axonal degeneration of the optic nerve $(\mathrm{ON})$ and apoptosis of retinal ganglion cells (RGCs). ${ }^{6-8,11}$

The mechanisms of axonal degeneration in autoim- mune inflammation are not fully understood but are likely to involve an accumulation of calcium ions $\left(\mathrm{Ca}^{2+}\right)$ in the axons. Indeed, several studies emphasize the involvement of $\mathrm{Ca}^{2+}$ in axonal degeneration in trauma, ${ }^{12}$ anoxia, ${ }^{13-15}$ ischemia, ${ }^{16}$ and inflammatory models. ${ }^{4}$ Under these pathological conditions, $\mathrm{Ca}^{2+}$ enters axons or neurons via ion-specific transport mechanisms such as voltage-dependent calcium channels (VDCCs), glutamate receptors, and/or reverse operation of the $\mathrm{Na}^{+} / \mathrm{Ca}^{2+}$ exchanger. In addition to a possible direct relevance for axonal degeneration in autoimmune inflammation, $\mathrm{Ca}^{2+}$ entry and VDCC activity may also be important for immune cell function: It has been shown that macrophages/microglia change membrane properties on activation. ${ }^{17,18}$ Further, it is
From the ${ }^{1}$ Department of Neurology, Georg-August University, Göttingen, Germany; ${ }^{2}$ Department of Neurobiology, Institute for Biological Research, Sinisa Stankovic, Belgrade, Serbia; ${ }^{3}$ Biomedizinische Nuclear Magnetic Resonance (NMR) Forschungs GmbH am MaxPlanck Institut für biophysikalische Chemie, Göttingen, Germany; ${ }^{4}$ Department of Neurology, University of the Saarland, Homburg/ Saar; ${ }^{5}$ Deutsche Forschungsgemeinschaft (DFG)-Research Center for Molecular Physiology of the Brain, Göttingen, Germany; and ${ }^{6}$ Department of Neurology, Medical University of Graz, Graz, Austria.

Address correspondence to Dr Diem, Department of Neurology, University of the Saarland, Kirrberger Strasse, Building 90, 66421
Homburg/Saar, Germany. E-mail: ricarda.diem@uniklinikumsaarland.de

Potential conflict of interest: Nothing to report.

I.G., S.B., and S.K.W. contributed equally to this work.

Additional Supporting Information may be found in the online version of this article.

Received Jul 14, 2008, and in revised form Jan 25, 2009. Accepted for publication Jan 30, 2009. Published online Mon 00, 2009, in Wiley InterScience (www.interscience.wiley.com). DOI: 10.1002/ ana. 21668 
known that $\mathrm{T}$ lymphocytes express beta regulatory subunits of VDCCs. ${ }^{19}$

In our study, we focused on the role of VDCCs during myelin oligodendrocyte glycoprotein-induced optic neuritis. We used manganese $\left(\mathrm{Mn}^{2+}\right)$-enhanced magnetic resonance imaging (MRI) in combination with VDCC blockers to identify those channels responsible for pathological $\mathrm{Ca}^{2+}$ influx into the ON. In parallel, we have performed in vivo $\mathrm{Ca}^{2+}$ imaging of the $\mathrm{ON}$, as well as expression analyses of VDCCs. The significance of an increased $\mathrm{Ca}^{2+}$ influx via N-type VDCCs for neurodegeneration, demyelination, and inflammation was further confirmed by administration of $\omega$-conotoxin GVIA ( $\omega$-CTX), a specific antagonist of $\mathrm{N}$-type VDCCs.

\section{Materials and Methods \\ Rats}

A total of 65 female brown Norway rats (8-10 weeks; Charles River, Sulzfeld, Germany) were used. Animal experiments have been approved by the authorities of Braunschweig, Germany.

\section{Experimental Autoimmune Encephalomyelitis Model}

Recombinant rat myelin oligodendrocyte glycoprotein was synthesized and injected as described elsewhere. ${ }^{20}$ Rats were scored daily for clinical signs of EAE. ${ }^{6}$ The cumulative score was calculated as the sum of daily scores.

\section{Quantification of Retinal Ganglion Cell Density}

A week before immunization, RGCs were labeled by injection of fluorogold into both superior colliculi. ${ }^{7}$ After the in vivo part of the experiments, rats were killed with $\mathrm{CO}_{2}$ and perfused with $4 \%$ paraformaldehyde in phosphate-buffered saline. Retinas were flat-mounted onto glass slides and RGC densities determined as described previously. ${ }^{6}$

\section{Optic Nerve Histopathology}

Animals were perfused with $4 \%$ paraformaldehyde, and ONs were embedded in paraffin. Histological evaluation was performed on $0.5 \mu \mathrm{m}$ sections stained with Luxol fast blue (LFB) and Bielschowsky silver impregnation. Demyelinated areas were determined as a percentage of the ON cross section. The surface area of the $\mathrm{ON}$ was measured using the AxioVision-4.5 software (Zeiss, Göttingen, Germany). Overview (200-fold) and high-magnification photographs $(1,000-$ fold) were made with a charge-coupled device camera (Color View-II) using an Axioplan-2 microscope (Zeiss). Axonal densities were determined in $\mathrm{ON}$ cross sections stained with Bielschowsky silver impregnation by point sampling using a 25 -point Olympus grid. Point sampling overcomes density artefacts arising with increased $\mathrm{ON}$ areas. ${ }^{2}$ Seventy-five points were superimposed on the whole of the $\mathrm{ON}$ cross section. The number of points crossing axons was measured as the fraction of the number of points of the stereological grid. $^{2}$ Axon reduction is given as the percentage of axon density compared with the average axon density in healthy ONs.
Neuropathological examinations were performed in a blinded manner.

To differentiate between axonal fibers with larger diameters $\left(>2 \mu \mathrm{m}^{2}\right)$ and those with smaller diameters $\left(\leq 2 \mu \mathrm{m}^{2}\right)$, we performed a slightly modified technique for fiber counts as DeLuca and colleagues ${ }^{21}$ described previously. In brief, high-magnification photographs $(\times 1000)$ were digitized and enhanced (AxioVision-4.5; Zeiss). We then performed manual counts of axons to exclude axonal spheroids from quantification. This was done to avoid a bias toward fibers of larger diameter, which would not have been possible using an Image software program for fiber counts. Manual counts of axons were performed in a blinded manner by two independent investigators with long-standing experience in the field of neuropathology.

\section{Immunohistochemistry on Optic Nerves}

Immunohistochemistry was performed on serial sections of paraffin-embedded ONs. As primary antibodies we used rabbit anti- $\alpha_{1 \mathrm{~B}} \quad(1: 1,000$; Sigma-Aldrich, Taufkirchen, Germany), mouse anti- $\beta$-amyloid precursor protein ( $\beta$-APP, Chemicon, Temecula, CA; 1:1,000), mouse anti-CD68 (1: 500, ED1; Serotec, Oxford, United Kingdom), mouse antiendothelial monocyte-activating polypeptide II (1:100; EMAP II; Abcam, Cambridge, United Kingdom), mouse anti-glial fibrillary acidic protein (1:100; GFAP; Dianova, Hamburg, Germany), mouse anti-myelin-2', $3^{\prime}$-cyclicnucleotide-3'-phosphodiesterase (myelin-CNPase) (1:200, SMI-91; Covance Princeton, NJ), mouse anti-phosphorylated neurofilament (1:1,000, SMI-31; Covance), or mouse anti-nonphosphorylated neurofilament $(1: 1,000$, SMI-32; Covance). Secondary biotinylated antibodies (Vector, Burlingame, CA) were used as follows: goat anti-rabbit $\operatorname{IgG}(1: 200)$, goat or horse anti-mouse IgG $(1: 200)$. In addition, we used Cy3-labeled goat anti-rabbit IgG (1:600; Jackson Immunoresearch, West Grove, PA), and Alexa 488-labeled goat anti-mouse IgG (1:400; Molecular Probes, Leiden, the Netherlands). Control sections were incubated without primary antibodies. Spinal cord sections served as positive controls. ${ }^{4}$ Stereological quantitative analyses of ED1- and $\alpha_{1 \mathrm{~B}}$-labeled serial sections were performed by counting labeled cells in 9 microscopic fields of $62,500 \mu \mathrm{m}^{2}$, each defined by a morphometric grid. The counts were performed by two investigators following a blind protocol.

\section{Analysis of Spinal Cord Lesions}

Histological evaluation was performed on paraformaldehydefixed, paraffin-embedded sections of spinal cords. Paraffin sections were stained with hematoxylin and eosin, LFB, and Bielschowsky silver impregnation to assess inflammation, demyelination, and axonal pathology. In adjacent serial sections, immunohistochemistry was performed with an antibody against $\beta$-APP $(1: 1,000$; Chemicon) and macrophages/ activated microglia (ED1; 1:1,000). Bound primary antibody was detected with a biotin-avidin technique as described previously. ${ }^{22}$ Control sections were incubated in the absence of primary antibody or with nonimmune rabbit serum. The following histopathological parameters were analyzed. The degree of demyelination was evaluated semiquantitatively for 
the spinal cord sections and scored as follows: traces of perivascular or subpial demyelination (0.5), marked perivascular or subpial demyelination (1), confluent perivascular or subpial demyelination (2), demyelination of half spinal cord cross section (3), and transverse myelitis (4). Quantitative assessment of ED1-positive cells and $\beta$-APP-positive axons was determined as described previously. ${ }^{23,24}$ In brief, $\beta$-APP-positive axons were evaluated by overlaying a morphometric grid on ED1/ $\beta$-APP-stained spinal cord cross sections at a magnification of $\times 900$. Values are expressed as positive cells or axons per square millimeters per total spinal cord cross section (axons $/ \mathrm{mm}^{2} /$ total spinal cord cross section). Two investigators performed the neuropathological examinations independently and in a blinded manner.

\section{Magnetic Resonance Imaging}

Thirty-three animals underwent MRI at day 14 after immunization. Anesthesia was induced by medetomidine $(0.25 \mathrm{mg} / \mathrm{kg}$ subcutaneously; Pfizer, Berlin, Germany) and ketamine $(25 \mathrm{mg} / \mathrm{kg}$ intravenously; Medistar, Hanover, Germany). After relaxation, the animals were intubated as described previously. ${ }^{25}$

MRI measurements were performed at 2.35 Tesla using an MRBR 4.7/400mm magnet (Magnex Scientific, Abington, United Kingdom) equipped with a DBX system (Bruker Biospin, Ettlingen, Germany). ${ }^{25}$ After acquisition of precontrast T1-weighted images, $\mathrm{MnCl}_{2}(50 \mu \mathrm{mol} / \mathrm{kg}$; SigmaAldrich) was applied in an aqueous solution via a vein catheter. $\mathrm{Mn}^{2+}$-enhanced, T1-weighted MRI was performed 10 minutes, 24 hours, and 48 hours after $\mathrm{MnCl}_{2}$ administration. Some animals additionally received the following VDCC or $\alpha$-amino-3-hydroxyl-5-methyl-4-isoxazolepropionate (AMPA)/kainate receptor blockers (single-bolus injection over 30-60 seconds) immediately before application of $\mathrm{MnCl}_{2}$ : diltiazem $(20 \mathrm{mg} / \mathrm{kg}$ intraperitoneally; SigmaAldrich), $\omega$-CTX (10 $\mu \mathrm{g} / \mathrm{kg}$ intravenously; Anaspec, San Jose, CA), amlodipine $(5 \mathrm{mg} / \mathrm{kg}$ orally; LKT-Laboratories, St. Paul, $\mathrm{MN})$, amiloride ( $100 \mu \mathrm{mol} / \mathrm{kg}$ intravenously; Sigma-Aldrich), $\omega$-agatoxin IVA $(20 \mu \mathrm{g} / \mathrm{kg}$ intravenously; Alomone, Jerusalem, Israel), or NBQX $(30 \mathrm{mg} / \mathrm{kg}$ intraperitoneally; TocrisBioscience, Ellisville, MO). Drug concentrations were chosen as described previously. ${ }^{26-30}$

For quantitative image analyses, MRI sections parallel to the ON (see Supplemental Fig 1A) were used to determine a suitable region of interest. Region-of-interest analyses were based on MRI signal intensities (SI) in the ON normalized to the intensity of nearby gray matter using Paravision 3.2 (Bruker Biospin, Ettlingen, Germany) (see Supplemental Fig 1B). The ratio of the normalized SI after and before application of $\mathrm{MnCl}_{2}$ was calculated to determine the efficiency of the applied antagonists to block respective $\mathrm{Ca}^{2+}$ channels.

\section{In Vivo Calcium Imaging}

Animals were anesthetized by chloralhydrate $(420 \mathrm{mg} / \mathrm{kg}$ intraperitoneally). Using a Hamilton syringe, we injected $3 \mu \mathrm{l}$ Oregon-Green-488 BAPTA-1 AM ester (OGB) into the vitreous body. OGB is taken up by RGCs, the cell bodies of the ON axons. After entering the cytoplasm of RGCs, OGB is hydrolyzed to a form that cannot easily pass through the cell membrane. Therefore, most of the OGB transported an-

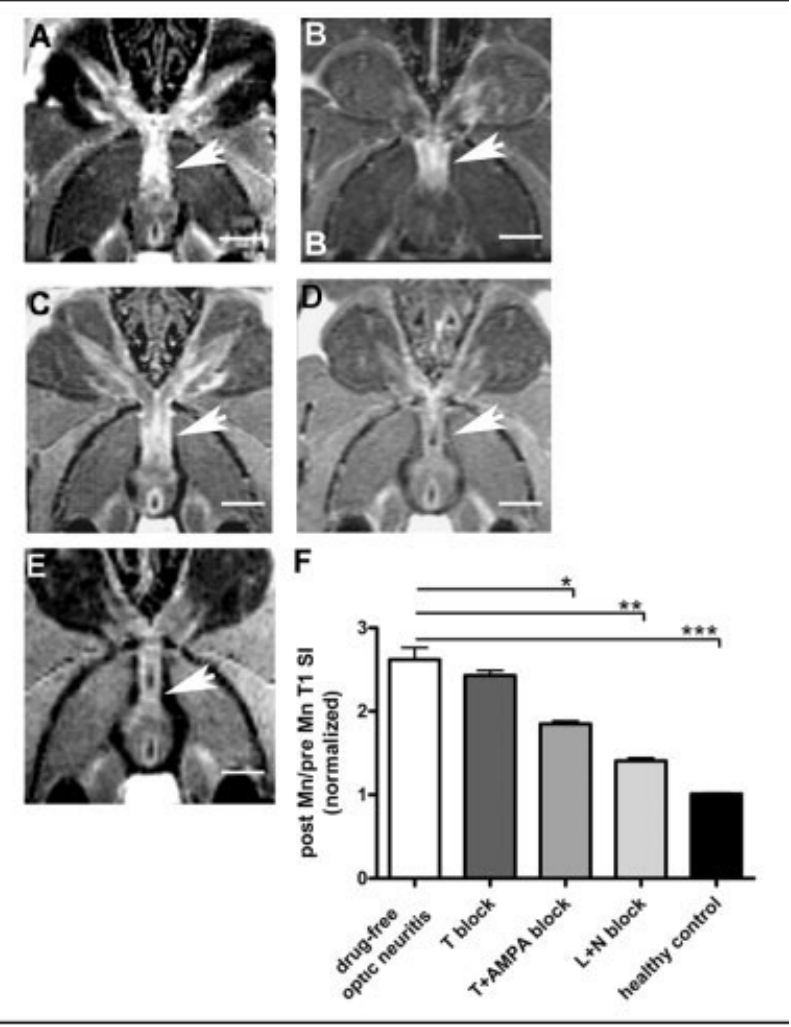

Fig 1. T1-weighted magnetic resonance images obtained 10 minutes after $\mathrm{MnCl}_{2}$ application show the effects of typespecific, voltage-dependent calcium channel (VDCC) blockers and an $\alpha$-amino-3-hydroxyl-5-methyl-4-isoxazole-propionate (AMPA) receptor antagonist on $\mathrm{Mn}^{2+}$-induced enhancement (MIE) within the optic nerves (ONs). (A) Drug-free optic neuritis. (B) T-type VDCC blockade did not reduce MIE. (C) The combination of a T-type VDCC blocker and an AMPA receptor antagonist led to reduction of MIE $(\mathrm{p}<0.05)$. (D) Inhibition of $L$ - and N-type VDCCs led to a highly significant reduction of MIE $(\mathrm{p}<0.01)$. (E) MIE was not observed in the ONs of a healthy sham-immunized rat. (F) Normalized signal intensity (SI) obtained from T1-weighted images (post Mn/pre Mn T1 SI) of the inflamed ONs without blocker (drug-free optic neuritis), with amiloride (T block), with amiloride and $N B Q X(T+A M P A$ block), with amlodipine $(L+N$ block), and of the ONs of healthy shamimmunized rats (healthy control). Arrowheads point to the left optic nerve in each animal. Error bars represent standard error of the means. ${ }^{*} \mathrm{p}<0.05$; $^{* *} \mathrm{p}<0.01 ;^{* * *} \mathrm{p}<0.001$. Scale bars $=2 \mathrm{~mm}$.

terogradely along $\mathrm{ON}$ axons is maintained within the intracellular space of the ON axons. After 2 hours, the orbita was opened and the $\mathrm{ON}$ exposed by longitudinal incision of the nerve sheath. A tie of fine surgical thread (10/0, Ethilon, Johnson Medical GmbH, Norderstedt, Germany) was placed around the $\mathrm{ON}$ to make sure that the tissue visualized was indeed the ON.

The rat was placed below an objective $(40 \mathrm{x} / 0.8 \mathrm{WPh} 2$; Zeiss), and the space between the objective and the $\mathrm{ON}$ was filled with $0.9 \% \mathrm{NaCl}$. OGB was excited at $488 \mathrm{~nm}$ and collected through a $522 \mathrm{~nm}$ band-pass filter using a fluorescence 
microscope (Axioplan-2; Zeiss). Fifty images (1/sec) were taken before inducing depolarization by intravitreal injection of $10 \mu \mathrm{l}$ of a $\mathrm{KCl}$ solution $(160 \mathrm{mM})$ to quantify the extent of photobleaching. Thirty minutes before inducing depolarization, $\omega$-CTX (Mobitec, Göttingen, Germany) was applied topically to the $\mathrm{ON}$ in a dose of $3 \mu \mathrm{g}$ per ON. ${ }^{31}$

The data were analyzed with ImageJ $1.36 b$ (http://rsb.info.nih.gov/ij/) measuring the integrated density (gray values of pixels) in a representative region of interest of the ON. As the baseline fluorescence activity varied from nerve to nerve, the baseline fluorescence intensity of each nerve was set to $100 \%$. The maximum fluorescence peak was set in relation to this baseline. The ON has some minor autofluorescence, which is much lower than the baseline fluorescence of the nerve loaded with OGB. Similarly, the baseline fluorescence of the nerve loaded with OGB was set in relation to the maximum fluorescence peak in each experiment and, therefore, should not have an effect on the calcium-triggered increase of fluorescence activity after $\mathrm{KCl}$ injection.

\section{Intracerebroventricular Infusion}

Sixteen rats were implanted with miniosmotic pumps and the respective brain infusion kits (model 2004; Alzet, Cupertino, CA). $\omega$-CTX $(6 \mu \mathrm{M})$ was diluted in artificial cerebrospinal fluid (Harvard Apparatus, Dover, MA). The control group received pumps containing only artificial cerebrospinal fluid. The pumps were primed for 40 hours at $37^{\circ} \mathrm{C}$ in $0.9 \%$ saline and implanted subcutaneously in the midscapular region. The tip of the infusion kit was placed into the right lateral ventricle $(0.9 \mathrm{~mm}$ caudal and $1.4 \mathrm{~mm}$ lateral to bregma, $3.6 \mathrm{~mm}$ below the dura mater). The minipumps yielded a constant rate of $0.25 \mu \mathrm{l} / \mathrm{hr}$ for 23 days in the pretreatment groups and for 8 days in the late-treatment groups. During these experiments, $\omega$-CTX was delivered at a concentration of $1.5 \mathrm{pmol} / \mathrm{hr}$ according to published protocols. ${ }^{32}$ After explantation of the pumps, the residual volume was measured.

\section{Statistics \\ $\mathrm{Mn}^{2+}$-induced enhancement (MIE) in the pilot MRI study was compared by one-way analysis of variance followed by Tukey's multiple-comparison Test. For larger samples, as in the main MRI study, we used Kruskal-Wallis nonparametric analysis of variance followed by Dunn's post hoc procedure. Histopathological and calcium imaging data, RGC densities, and neurological scores were analyzed by the nonparametric Mann-Whitney two-tailed test. The Spearman's two-tailed test was used to correlate $\alpha_{1 \mathrm{~B}}$ expression with demyelination or axonal reduction. All statistical analyses were performed using GraphPad Prism software, version 4.00 (GraphPad Software, San Diego, CA).}

\section{Results}

High-Voltage-Activated Calcium Channels Mediate $\mathrm{Mn}^{2+}$ Uptake into the Optic Nerve

$\mathrm{Mn}^{2+}$ is an analog of $\mathrm{Ca}^{2+}$ and serves as an MRI contrast agent. We injected $\mathrm{MnCl}_{2}$ to detect pathophysiological changes related to $\mathrm{Ca}^{2+}$ influx in rats with optic neuritis by MRI. To investigate possible routes of
$\mathrm{MnCl}_{2}$ entry into the $\mathrm{ON}$, we modified a previously established MRI protocol. ${ }^{25}$ VDCC and AMPA/kainate receptor antagonists were applied immediately before administration of $\mathrm{MnCl}_{2}$.

Initially, the effects of the following antagonists were investigated: (1) an AMPA/kainate receptor antagonist (NBQX), (2) a high-voltage-activated VDCC antagonist specific for L- and N-type VDCCs (amlodipine), and (3) a low-voltage-activated VDCC antagonist acting on T-type VDCCs (amiloride).

Application of the T-type blocker still allowed for an enhancement of $\mathrm{Mn}^{2+}$ within the inflamed $\mathrm{ON}$ in magnetic resonance images taken 10 minutes after application of $\mathrm{MnCl}_{2}$ (Figs 1B, F). However, significantly reduced MIE was seen after application of the T-type blocker in combination with the AMPA/kainate receptor antagonist $(p<0.05$; see Figs $1 \mathrm{C}, \mathrm{F})$. A highly significant reduction of MIE could be observed after application of the $\mathrm{L}+\mathrm{N}$ blocker $(p<0.01$; see Figs 1D, F) when compared with rats with optic neuritis that received $\mathrm{MnCl}_{2}$ alone (see Figs 1A, F). Healthy ONs of sham-immunized rats $(n=6)$ showed no MIE after $\mathrm{Mn}^{2+}$ application, which was significantly different in comparison with untreated inflamed ONs $(p<0.001)$ (see Figs 1E, F).

The normalized SI of the ONs was measured before and 10 minutes after application of $\mathrm{MnCl}_{2}$, and their ratio was used to quantify the effect of the antagonists. Mean values \pm standard error of the mean (see Fig $1 F$ ) were $2.62 \pm 0.14$ in rats with drug-free optic neuritis $(\mathrm{n}=4), 2.43 \pm 0.06$ in animals receiving the T-type blocker $(\mathrm{n}=3), 1.85 \pm 0.04$ after combined application of the T-type blocker and the AMPA/kainate receptor antagonist $(\mathrm{n}=3), 1.40 \pm 0.04$ for the $\mathrm{L}+\mathrm{N}$ blocker $(\mathrm{n}=3)$, and $1.01 \pm 0.01$ in healthy shamimmunized animals $(\mathrm{n}=6)$.

\section{$\mathrm{Mn}^{2+}$ Enters the Optic Nerve via N-Type Voltage-} Dependent Calcium Channels

Because the most prominent inhibition of $\mathrm{Mn}^{2+}$ uptake was observed after application of the $\mathrm{L}+\mathrm{N}$-type blocker, our objective was to further dissect the highvoltage-activated VDCCs involved in $\mathrm{Mn}^{2+}$ influx, namely, L-type, P/Q-type, and $\mathrm{N}$-type, with the use of specific antagonists. These included diltiazem, an inhibitor of L-type VDCCs, ${ }^{29} \omega$-CTX, a blocker for $\mathrm{N}$-type VDCCs, ${ }^{28}$ and $\omega$-agatoxin IVA, an inhibitor of P/Q-type VDCCs. ${ }^{28}$ The antagonists were applied to those animals with abnormalities in T1-weighted magnetic resonance images (increased $\mathrm{ON}$ diameter and hypointense T1-weighted SI).

A T1-weighted image of inflamed $\mathrm{ONs}$ of an untreated animal 10 minutes after $\mathrm{Mn}^{2+}$ application is presented in Figure 2A. Figures $2 \mathrm{~B}$ to $\mathrm{D}$ show $\mathrm{ONs}$ of rats that additionally received the L-type (see Fig 2B), the P/Q-type (see Fig 2C), or the N-type 
blocker (see Fig 2D). Whereas the normalized SI ratios in animals receiving the L-type (1.70 \pm 0.20 ; $\mathrm{n}=8)$ or P/Q-type blocker $(1.82 \pm 0.09 ; \mathrm{n}=9)$, although reduced, did not significantly differ from drug-free optic neuritis $(2.03 \pm 0.13 ; \mathrm{n}=14)$, MIE in the ONs was significantly reduced after application
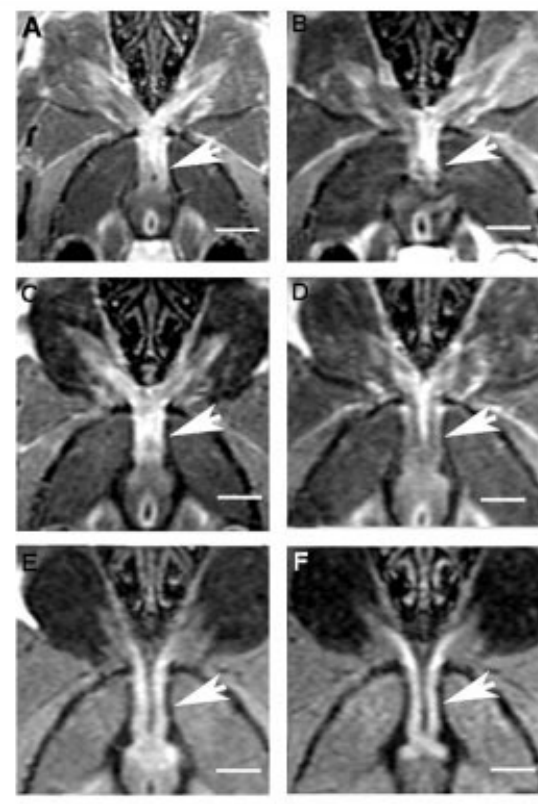

G

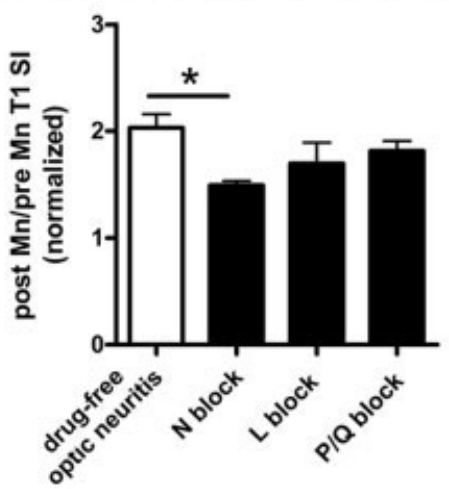

Fig 2. T1-weighted magnetic resonance images obtained after $\mathrm{MnCl}_{2}$ application demonstrating the effects of type-specific, high-voltage-activated (HVA) voltage-dependent calcium channel (VDCC) blockers on $\mathrm{Mn}^{2+}$-induced enhancement (MIE) within the inflamed optic nerves $(O N s)$. ( $(A-D)$ Images were taken 10 minutes after application of $\mathrm{MnCl}_{2}$ without a blocker (A), with the L-type VDCC blocker (B), with the $P / Q$-type VDCC blocker $(C)$, and with the N-type VDCC blocker (D). Note that application of the N-type VDCC blocker suppresses MIE within the ONs. (E, F) After degradation of the N-type VDCC blocker (after 24 hours), MIE of the inflamed ONs recovers $(E)$ and retains up to 48 hours (F). (G) Normalized signal intensities (SIs) of the ONs without blocker (drug-free optic neuritis), with $\omega$-conotoxin GVIA $(\omega-C T X)(N$ block), with diltiazem (L block), and with $\omega$-agatoxin IVA (P/Q block). Arrowheads point to the left optic nerve in each animal. Error bars represent standard error of the means $\left({ }^{*} \mathrm{p}<0.05\right)$. Scale bars $=2 \mathrm{~mm}$. of the N-type blocker $(1.49 \pm 0.04 ; \mathrm{n}=7 ; p<$ 0.05 ; see Fig $2 \mathrm{G}$ ). Magnetic resonance images presented in Figures 2A to $\mathrm{D}$ were taken 10 minutes after administration of $\mathrm{MnCl}_{2}$.

In this context, it should be mentioned that the halflife of $\omega$-CTX is $4.61 \pm 0.59$ hours. ${ }^{33}$ Therefore, MRI performed 24 and 48 hours later demonstrated an MIE also in ONs with suppressed enhancement 10 minutes after injection of the N-type blocker. Quantitative analyses showed that the normalized SI relative to the precontrast image of the ONs both at 24 (1.35 \pm $0.04 ; \mathrm{n}=5)$ and 48 hours after $\mathrm{MnCl}_{2}$ application $(1.14 \pm 0.09 ; \mathrm{n}=5)$ (see Figs $2 \mathrm{E}, \mathrm{F}$ ) was not significantly different from that of animals that received $\mathrm{MnCl}_{2}$ without a blocker $(1.42 \pm 0.11$ at 24 hours; $\mathrm{n}=5 ; 1.41 \pm 0.12$ at 48 hours; $\mathrm{n}=3$ ).

\section{N-Type Voltage-Dependent Calcium Channel Expression Correlates with Demyelination}

Because blockade of N-type VDCCs reduced $\mathrm{Mn}^{2+}$ uptake into inflamed ONs, N-type VDCC expression was investigated further. Immunohistochemistry for $\alpha_{1 \mathrm{~B}}$, the pore-forming subunit of N-type VDCCs, showed a significant difference in both degree and pattern of N-type VDCC expression between healthy and inflamed ONs. In healthy, myelinated ONs (Fig $3 \mathrm{~A}$ ), a modest degree of $\alpha_{1 \mathrm{~B}}$ immunoreactivity was detected (see Fig 3B) and quantified as the number of $\alpha_{1 \mathrm{~B}}$-positive sites per square millimeter (493.22 \pm $14.79 ; \mathrm{n}=8$ ) (see Fig 3F). However, a significant upregulation of expression was seen during optic neuritis $(1,323.38 \pm 79.51 ; \mathrm{n}=10$; see Figs $3 \mathrm{C}, \mathrm{D})$ compared with the ONs of sham-immunized rats $(p<0.001)$ (see Fig 3F). Furthermore, a significant correlation between the number of $\alpha_{1 \mathrm{~B}}$-positive sites per square millimeter and the percentage of demyelination was detected $(r=0.76 ; p<0.001 ; \mathrm{n}=26)$ (see Fig 3G). A significant correlation was further observed between the number of $\alpha_{1 \mathrm{~B}}$-positive sites per square millimeter and the percentage of axonal reduction $(r=0.66 ; p<0.001 ; \mathrm{n}=26)$ (see Fig 3H). In parallel with the $\alpha_{1 \mathrm{~B}}$ staining of serial ON sections, spinal cord sections from healthy rats served as positive controls (see Fig 3E). ${ }^{4}$

\section{N-Type Voltage-Dependent Calcium Channel Expression Correlates with Immunoreactivity for $\beta$ - Amyloid Precursor Protein, Nonphosphorylated Neurofilament, and with ED1- and EMAP II- Positive Macrophages/Microglia}

We further investigated the relation between the expression of $\alpha_{1 \mathrm{~B}}$ and $\beta$-APP, a marker of disturbed axonal transport, in optic neuritis. Fluorescence microscopy showed a colocalization of $\alpha_{1 \mathrm{~B}}$ and $\beta$-APP, as shown in Figure 4A. In addition, we detected expression of $\alpha_{1 \mathrm{~B}}$ in nonphosphorylated $\mathrm{ON}$ axons stained 


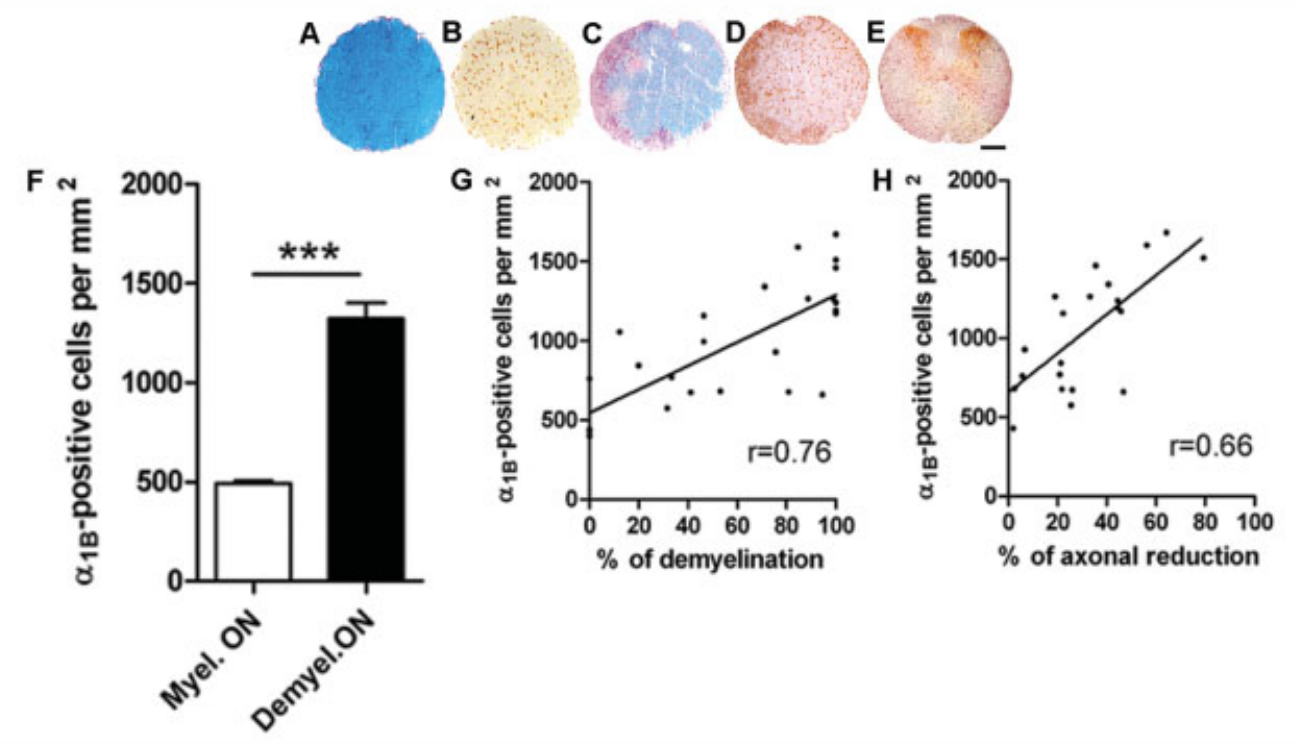

Fig 3. Expression of the pore-forming subunit of $N$-type voltage-dependent calcium channels (VDCCs) ( $\left.\alpha_{1 B}\right)$ in the optic nerves $(O N s)$ of healthy rats and rats with optic neuritis. (A) Luxol fast blue (LFB) staining of a healthy ON, showing complete myelination (blue area). (B) Adjacent serial section of the $O N$ shown in (A) stained for $\alpha_{1 B}$. (C) LFB staining of a representative ON from a rat with myelin oligodendrocyte glycoprotein (MOG)-induced optic neuritis. (D) Adjacent serial section of the ON shown in (C) stained for $\alpha_{1 B}$. Note the upregulation of $\alpha_{1 B}$ in the demyelinated areas. (E) Cross section of a healthy rat spinal cord, showing intense $\alpha_{1 B}$ immunoreactivity in regions of high synaptic density. Spinal cord served as control for the efficacy of the $\alpha_{1 B}$ staining. (F) Quantification of $\alpha_{1 B}$-positive sites per square millimeter in myelinated and demyelinated $O N_{s}{ }^{* * *} \mathrm{p}<0.001$. (G) Correlation between the numbers of $\alpha_{1 B}$-positive sites per square millimeter and the percentage of demyelination. (H) Correlation between the numbers of $\alpha_{1 B}$-positive sites per square millimeter and the percentage of axonal reduction. Scale bar $=100 \mu m(A-D)$; $400 \mu m(E)$.

with SMI-32 (see Fig 4C) indicating that N-type VDCCs are not only expressed in areas of transport failure but also in nonspheroided, degenerating axons. In contrast, no expression of $\alpha_{1 \mathrm{~B}}$ was seen in healthy $\mathrm{ON}$ axons stained with SMI-31, a marker of phosphorylated, intact axons (see Fig 4B).

However, many $\alpha_{1 B}$-positive cells were $\beta$-APP- or SMI-32-negative, suggesting that another cell type also expresses N-type VDCCs. Double immunohistochemistry for $\alpha_{1 \mathrm{~B}}$ and ED1, as well as for $\alpha_{1 \mathrm{~B}}$ and EMAP II, another marker of macrophages/activated microglia, ${ }^{34,35}$ showed strong colocalization (see Figs $4 \mathrm{E}, \mathrm{F}$ ), but there were also a few $\alpha_{1 \mathrm{~B}}$-immunoreactive cells that were ED1- and EMAP II-negative. Furthermore, some immunoreactivity was detected on astrocytes (see Fig 4D). In contrast, no colocalization was seen between $\alpha_{1 \mathrm{~B}}$ and either CNPase, a marker of oligodendrocytes (see Figs 4G, H), or CD3, a marker for $\mathrm{T}$ lymphocytes (data not shown).

\section{$\omega$-CTX Suppresses $\mathrm{Ca}^{2+}$ Influx into the Inflamed Optic Nerve}

To investigate whether $\omega$-CTX not only suppresses $\mathrm{Mn}^{2+}$ but also $\mathrm{Ca}^{2+}$ influx into the ON, we performed in vivo $\mathrm{Ca}^{2+}$ imaging in rats 15 days after immunization. Measurements of fluorescence signal in- tensity changes after $\mathrm{KCl}$-induced depolarization demonstrated a significantly increased influx of $\mathrm{Ca}^{2+}$ into the $\mathrm{ONs}$ in rats with optic neuritis (112.3 \pm $2.4 \% ; \mathrm{n}=13$; Figs $5 \mathrm{C}, \mathrm{D}, \mathrm{G})$ in comparison with ONs in healthy sham-immunized animals (104.7 \pm $0.9 \% ; \mathrm{n}=9 ; p<0.05$; see Figs $5 \mathrm{~A}, \mathrm{~B}, \mathrm{G})$. After application of $\omega$-CTX to inflamed ONs, the depolarization-induced influx of $\mathrm{Ca}^{2+}$ was significantly inhibited $(100.4 \pm 0.2 \%$; $\mathrm{n}=7$; see Figs $5 \mathrm{E}-\mathrm{G}$; $p<$ $0.001)$ in comparison with inflamed ONs after application of $\mathrm{NaCl}$. Furthermore, inflamed ONs after application of $\omega$-CTX showed significantly less fluorescence signal intensity than healthy ONs $(p<0.01$; see Fig 5G).

\section{Application of $\omega$-CTX Ameliorates Optic Neuritis} After observing that $\mathrm{N}$-type VDCCs are upregulated in degenerating axons and are expressed on macrophages/ microglia during optic neuritis, we tested whether these phenomena play a role in neurodegeneration. $\omega$-CTX was continuously applied via osmotic minipumps to the cerebrospinal fluid, and the extent of neurodegeneration was subsequently assessed by histopathology. Two treatment paradigms were compared: In the first two groups ("PRE"), delivery of $\omega$-CTX or vehicle started 2 days before immunization and was continued 

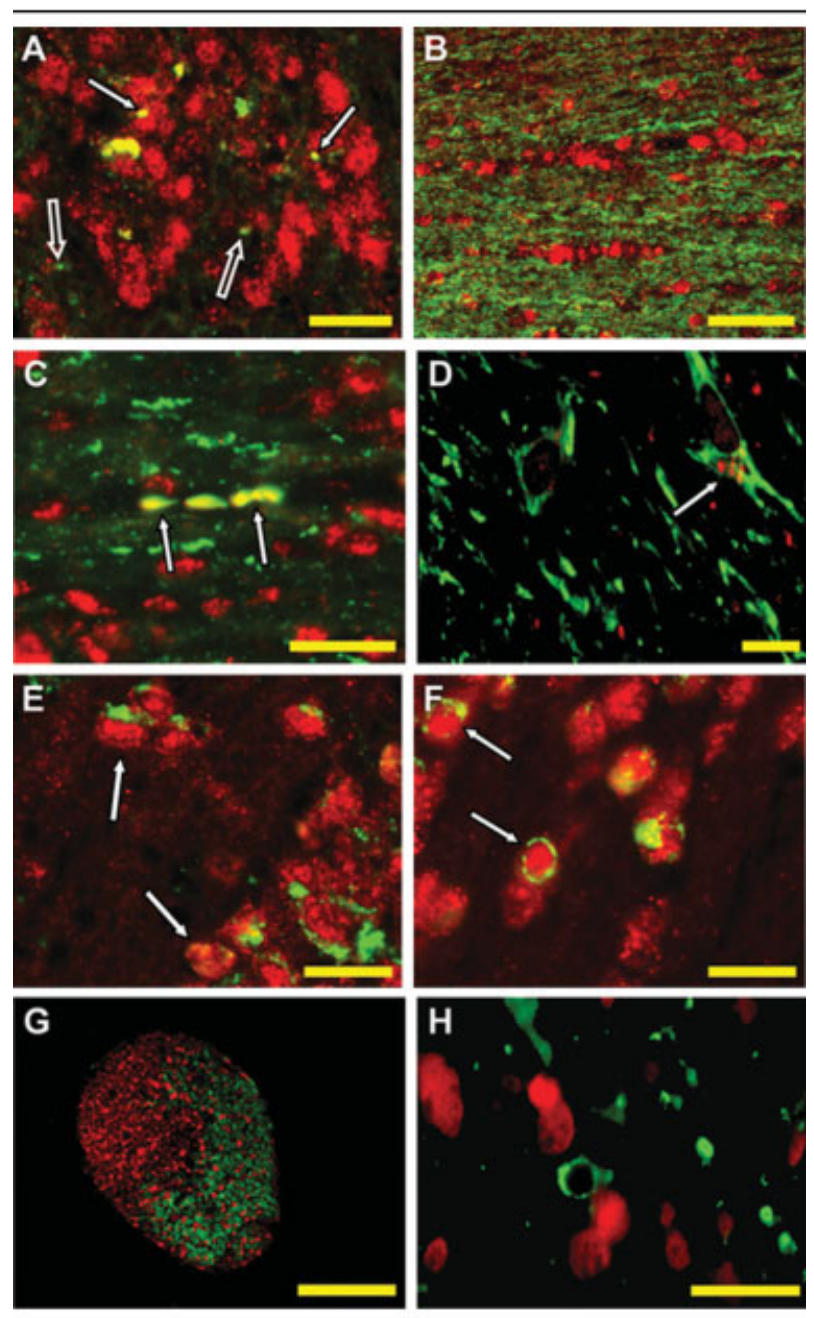

Fig 4. Immunofluorescence of $\alpha_{1 B}$ in healthy optic nerves and during optic neuritis. (A) Colocalization of $\beta$-amyloid precursor protein ( $\beta-A P P)$ (green) and $\alpha_{1 B}$ (red) as seen in a merged fluorescence microscopy image (closed arrows indicate colocalization of $\beta-A P P$ and $\alpha_{1 B}$; open arrows indicate $\alpha_{1 B^{-}}$ negative, $\beta$-APP-positive axonal profiles). (B) Healthy optic nerve $(O N)$ stained with the phosphorylated neurofilament marker SMI-31 (green) and $\alpha_{1 B}$ (red), showing no colocalization. (C) ON from a rat with optic neuritis stained with SMI-32 (green), which labels nonphosphorylated axons, and $\alpha_{1 B}$ (red) (arrows indicate points of colocalization). (D) Some glial fibrillary acidic protein-positive cells (green) were observed to express $\alpha_{1 B}$ (red) (closed arrows indicate a colabeled cell). (E, F) Colocalization of the microglial/macrophage markers EDI (E, green) and EMAP II ( $F$, green) with $\alpha_{1 B}$ ( $E, F$ red) during optic neuritis. Arrows indicate colabeled cells. $(G, H)$ Colocalization between the oligodendrocytic marker CNPase (green) and $\alpha_{1 B}$ (red) was not observed ( $H$ is a higher-power image of $G)$. Scale bars $=20 \mu \mathrm{m}(A, D-F$, $H) ; 50 \mu m(B, C) ; 100 \mu m(G)$.

until day 21 after immunization, corresponding to a time point 1 week after disease manifestation. In the next two groups ("LATE"), delivery of $\omega$-CTX or ve- hicle started at EAE onset and was continued for 1 week.

In the PRE group, axon counts (given as the percentage of axon density compared with the average axon density in healthy ONs; $\mathrm{n}=12$ ) were improved when compared with vehicle-treated animals ( $\omega$-CTX
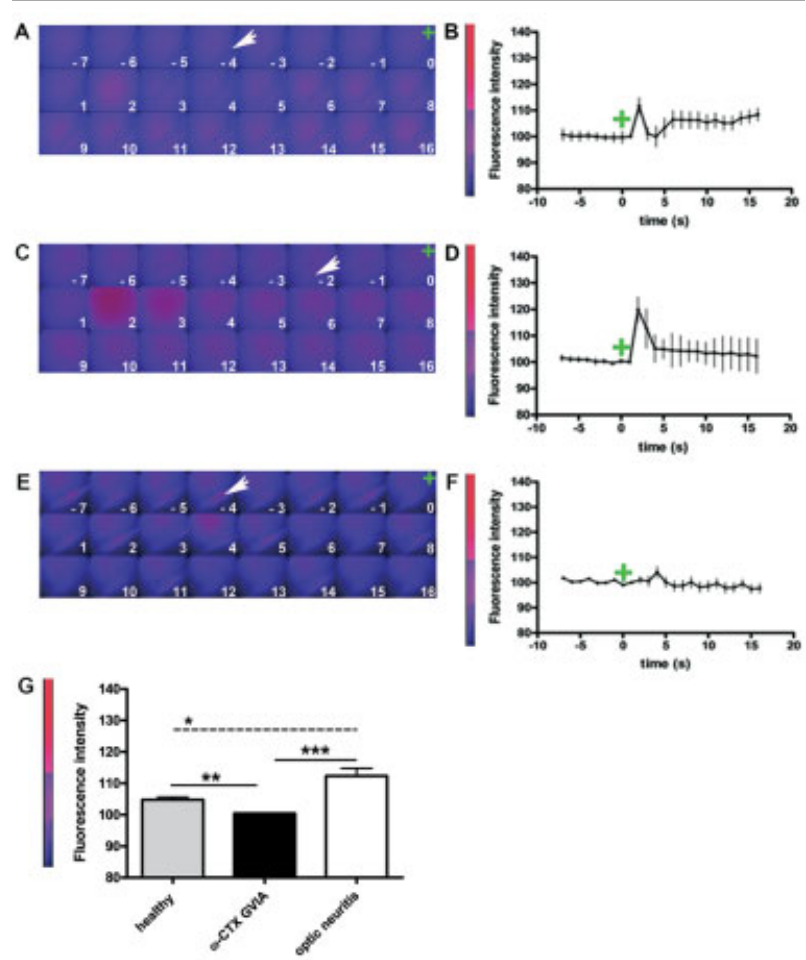

Fig 5. In vivo calcium imaging of rat optic nerves (ONs) after KCl-induced depolarization. ( $A, C, E$ ) Microscopic view of a part of the $O N$, showing Ca-sensitive fluorescence intensity (FI) before and after $\mathrm{KCl}$ application. The time line in seconds is shown by numbers. Green crosses indicate time of $\mathrm{KCl}$ application (time O) in the graphs and images. A thread (white arrowheads), placed around the ON, served as a spatial marker to ensure imaging of the same region during the whole duration of the measurements. (A) Healthy ON showing a mild FI increase after $\mathrm{KCl}$ application (segment 2). (B) $F I$ in healthy ONs plotted against time. (C) Inflamed ON without application of $\omega$-conotoxin GVIA ( $\omega$-CTX) showing an increase in FI after depolarization (segments 2-3). (D) FI in inflamed ONs without $\omega$-CTX plotted against time. (E) Inflamed ON treated topically with $\omega$-CTX showing mild FI increase after $\mathrm{KCl}$ application (segments 3-4). (F) FI in inflamed ONs with $\omega$-CTX plotted against time. Note the reduction in FI after application of KCl when compared with $(C, D)$. (G) Quantification of FI changes in ONs from healthy rats and from rats suffering from optic neuritis with and without application of $\omega$-CTX. Application of the N-type voltage-dependent calcium channel (VDCC) blocker led to highly significant reduction of FI. Healthy rats and animals with optic neuritis not treated with $\omega$-CTX received normal saline instead of blocker-containing solution. Error bars represent standard error of the means. ${ }^{*} \mathrm{p}<0.05$; ${ }^{*} \mathrm{p}<0.01$; *** $\mathrm{p}<0.001$. 

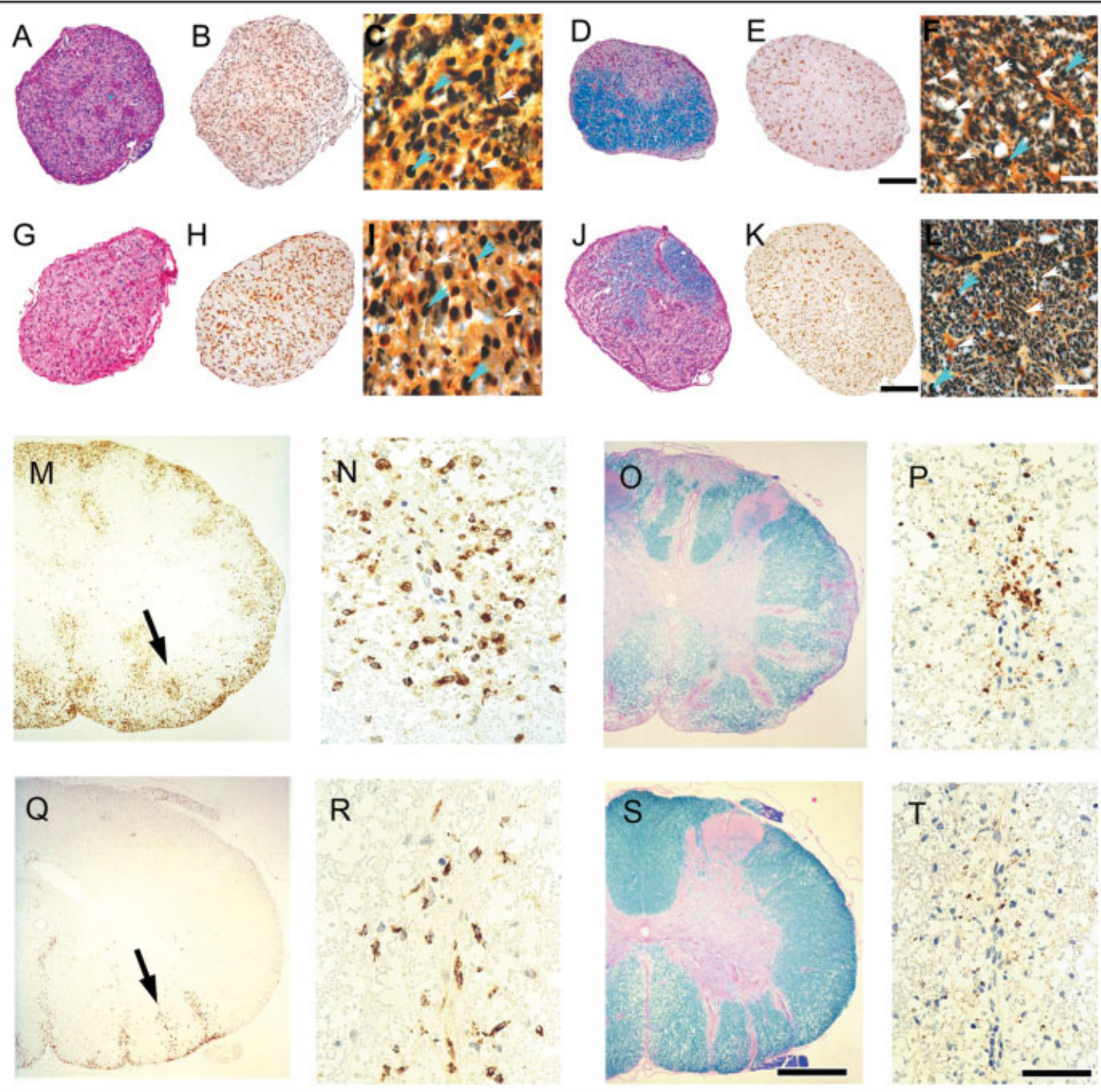

Fig 6. Effects of $\omega$-conotoxin GVIA ( $\omega$-CTX) application on myelin oligodendrocyte glycoprotein (MOG)-induced optic neuritis and spinal cord lesions. Application of vehicle $(A-C, G-I, M-P)$ or $\omega-C T X(D-F, J-L, Q-T)$ was either started two days before immunization $(A-F, M-T)$ or given from the day of disease onset onward $(G-L)$ and was continued over 3 weeks. $(A, D, G, J)$ Luxol fast blue (LFB) staining of optic nerves (ONs) showing the extent of demyelination (purple areas). Blue areas indicate intact myelin. Note the decrease in demyelination in both ONs treated with $\omega$-CTX $(D, J) .(C, F, I, L)$ Bielschowsky staining of ONs indicating the extent of axonal degeneration. White arrowheads point to normal-appearing axons, whereas green arrowheads show infiltrating macrophages. Note the higher density of axons in both $\omega$-CTX-treated ONs ( $F, L)$. (B, E, H, K) Immunohistochemistry for $\alpha_{I B}$ shows generally decreased expression in both $\omega$-CTX-treated $O N_{S}(E, K)$ in comparison with the vehicle-treated ONs $(B, H) .(M, N, Q, R)$ Spinal cord sections obtained from a vehicle-treated rat $(M, N)$ and a rat from the $\omega$-CTX PRE-treated group $(Q, R)$. Areas indicated by black arrows $(M, Q)$ have been selected for higher magnification $(N, R)$. Note that the vehicletreated animal exhibited marked infiltration with ED1-positive cells perivascularly, in the meninges and in the parenchyma adjacent to the pia mater $(M, N)$, whereas after $\omega$-CTX treatment, infiltration with ED1-positive cells was sparse $(Q, R) .(O, S) L F B$ stainings of spinals cords showed confluent perivascular and subpial demyelination after vehicle treatment $(O)$. In rats treated with $\omega$-CTX, demyelination was restricted to small perivascular rims (S). (P, T) Spinal cord sections stained for $\beta$-amyloid precursor protein $(\beta-A P P)$. In animals treated with $\omega$-CTX, $\beta$-APP-positive axons were only occasionally detectable $(T)$. (P, T) Panels represent the same areas of the spinal cord as shown in $(N, R)$. Scale bars $=100 \mu m(A, B, D, E, G, H, J, K) ; 20 \mu m(C, F, I, L)$; $300 \mu m(M, O, Q, S) ; 50 \mu m(N, P, R, T)$.

treated, $9.6 \pm 3.6 \%, \mathrm{n}=8$; vehicle treated, $52.8 \pm$ $8.2 \%, \mathrm{n}=5 ; p<0.01$; Figs $6 \mathrm{C}, 6 \mathrm{~F}$, and $7 \mathrm{C})$. In the LATE group, a trend toward increased axon counts was seen after $\omega$-CTX treatment; however, this differ- ence was not statistically significant ( $\omega$-CTX treated, $13.9 \pm 6.7 \%, \mathrm{n}=8$; vehicle treated, $39.72 \pm 6.3 \%$, $\mathrm{n}=5 ; p=0.06$; see Figs 6I, 6L, and 7D).

We further detected significantly reduced demyeli- 


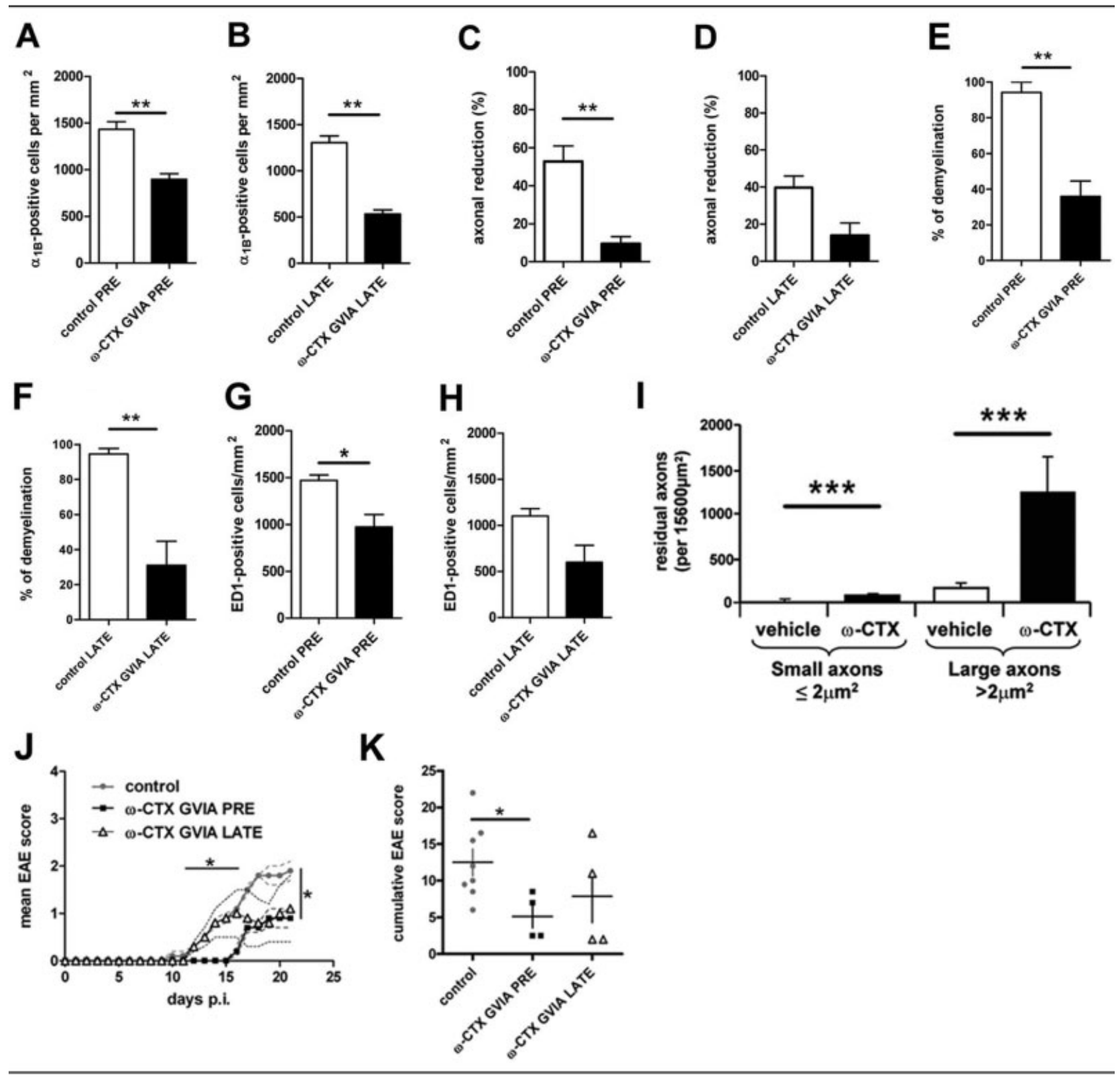

Fig 7. Quantitative analyses of optic nerve (ON) histopathology and clinical course after PRE and LATE $\omega$-conotoxin GVIA ( $\omega$ $C T X)$ treatment in comparison with the vehicle-treated control groups. $(A, B) \alpha_{1 B}$ expression is significantly reduced in the $\omega$-CTX-treated groups, both in PRE (A) and LATE (B) treatment. (C, D) Percentage of axonal reduction is significantly reduced after PRE treatment (C), whereas in the LATE treatment group (D), there is a strong decreasing trend. (E, F) Percentage of demyelination is significantly reduced in the $\omega$-CTX-treated groups, both after PRE (E) and LATE $(F)$ treatment. $(G$, H) The number of ED1-positive cells is significantly reduced after $\omega$-CTX PRE treatment (G). In the LATE group, there is a strong trend toward lower numbers of ED1-expressing cells after $\omega$-CTX treatment (H). (I) Analysis of residual ON axons with different diameters after vehicle or $\omega$-CTX treatment. Differentiation between axons with larger diameter $\left(>2 \mu m^{2}\right)$ and those with smaller diameter $\left(\leq 2 \mu \mathrm{m}^{2}\right)$ demonstrated highly significant differences between the groups. (J, K) Mean clinical scores (J) and mean cumulative scores $(K)$ were significantly lower in the group that received $\omega-C T X$ as a PRE treatment. The onset of experimental autoimmune encephalomyelitis (EAE) was significantly delayed in the $\omega$-CTX PRE-treated group as well (J). For clearer presentation, the animals from the control groups are pooled together. Error bars in $(A-I)$ and dotted lines in J represent standard error of the means. ${ }^{*} \mathrm{p}<$ $0.05 ;{ }^{* *} \mathrm{p}<0.01 ;{ }^{* *} \mathrm{p}<0.005$. p.i. $=$ postimmunization.

nation in both groups receiving $\omega$-CTX compared with the vehicle-treated groups $(\omega$-CTX PRE, $35.9 \pm$ 8.7\%, $\mathrm{n}=8$; vehicle PRE, $94.2 \pm 5.8 \%, \mathrm{n}=5 ; p<$
0.01 ; see Figs 6A, 6D, and 7E; $\omega$-CTX LATE, $31.0 \pm 13.7 \%, \mathrm{n}=8$; vehicle LATE, $94.5 \pm 3.2 \%$, $\mathrm{n}=5 ; p<0.01$; see Figs 6G, 6J, and 7F). In addi- 
tion, we found significantly reduced numbers of infiltrating macrophages/microglia (given as ED1positive cells $/ \mathrm{mm}^{2}$ ) in the ONs after PRE treatment $(\omega$-CTX PRE, $975.3 \pm 130.6, \mathrm{n}=8$; vehicle PRE, $1,471 \pm 58.7, \mathrm{n}=5 ; p<0.05$; see Fig 7G). In the LATE group treated with $\omega$-CTX, there was a trend toward reduced inflammatory infiltration within the ONs (see Fig 7H). RGC counts did not differ between the $\omega$-CTX- and vehicle-treated groups (data not shown).

Quantitative analysis of $\alpha_{1 \mathrm{~B}}$ immunoreactivity demonstrated a significant reduction in the number of $\alpha_{1 \mathrm{~B}}$-positive sites per square millimeter in both the PRE and LATE $\omega$-CTX-treated groups. In the PRE $\omega$-CTX-treated group, the number of $\alpha_{1 \mathrm{~B}}$-positive sites per square millimeter was $899.7 \pm 57.7(\mathrm{n}=8)$, whereas for the vehicle-treated group, the value was $1,434 \pm 80.4(\mathrm{n}=5, p<0.01$; see Fig 7A). For the LATE treatment, the values in the $\omega$-CTX-treated group were $532.8 \pm 44.9(\mathrm{n}=8)$, whereas the vehicle-treated controls had 1,306 $\pm 72.9 \alpha_{1 \mathrm{~B}^{-}}$ positive sites per square millimeter $(\mathrm{n}=5, p<0.01)$ (mean \pm standard error of the mean; see Fig 7B). $\mathrm{ON}$ sections from the different groups stained for $\alpha_{1 \mathrm{~B}}$ are given in Figures $6 \mathrm{~B}, \mathrm{E}, \mathrm{H}$, and $\mathrm{K}$. In parallel, spinal cord sections of healthy rats treated with $\omega$-CTX or vehicle ( $\mathrm{n}=4$ each) were stained for $\alpha_{1 \mathrm{~B}}$. The expression of $\alpha_{1 \mathrm{~B}}$ in these groups did not differ (data not shown), indicating that binding of $\omega$-CTX does not inhibit binding of the specific $\mathrm{N}$-type VDCC antibody.

To examine a differential effect of $\omega$-CTX on axon fibers of different diameters, we categorized remaining axons within demyelinated areas of the ONs as either large or small, using a size range of more than $2 \mu \mathrm{m}^{2}$ for the large fibers and $\leq 2 \mu \mathrm{m}^{2}$ for the small ones. Significantly more remaining axons of smaller diameter were observed in both $\omega$-CTX-treated groups when compared with vehicle-treated animals $(p<0.005$; see Fig 7I). Likewise, comparing remaining axons of larger diameter, we detected a significant difference between $\omega$-CTX- and vehicle-treated animals $(p<0.005$; see Fig 7I). However, the ratio of larger-diameter to smaller-diameter axons was 1:10.45 in the vehicletreated animals (both groups were analyzed together) and $1: 19.11$ in the $\omega$-CTX-treated animals, demonstrating a greater protective effect of $\omega$-CTX on smaller-diameter axons.

\section{Clinical Disease Course and Spinal Cord Lesions under $\omega$-CTX Treatment}

For the PRE treatment, disease onset was significantly delayed in the group that received $\omega$-CTX (day $15.8 \pm$ 0.9 after immunization; $\mathrm{n}=4$ ) in comparison with the control group $(13.0 \pm 0.7 ; \mathrm{n}=4 ; p<0.05)$, and the cumulative score was significantly reduced $(\omega$-CTX
Table. Summary of Histopathological Analyses of the Spinal Cord

\begin{tabular}{|c|c|c|}
\hline Analysis & Mean \pm SEM & $p$ \\
\hline Demyelination score & & 0.031 \\
\hline$\omega-\mathrm{CTX}$ & $0.50 \pm 0.129$ & \\
\hline Vehicle & $1.25 \pm 0.25$ & \\
\hline ED1-positive cells $/ \mathrm{mm}^{2}$ & & 0.046 \\
\hline$\omega-$ CTX & $214.63 \pm 100.96$ & \\
\hline Vehicle & $642.40 \pm 157.60$ & \\
\hline APP-positive axons $/ \mathrm{mm}^{2}$ & & 0.025 \\
\hline$\omega-\mathrm{CTX}$ & $14.03 \pm 10.07$ & \\
\hline Vehicle & $70.00 \pm 22.65$ & \\
\hline \multicolumn{3}{|c|}{$\begin{array}{l}\text { Summary of inflammation, demyelination, and acute axonal } \\
\text { injury in the spinal cord in vehicle-treated compared with } \omega \text { - } \\
\text { conotoxin GVIA ( } \omega \text {-CTX)-treated animals (the PRE and } \\
\text { LATE groups were analyzed together). Quantitative analyses of } \\
\text { the number of ED1-positive cells (activated macrophages/ } \\
\text { microglia), expressed as ED1-positive cells per square } \\
\text { millimeter per total cross section of the spinal cord, and the } \\
\text { number of } \beta \text {-amyloid precursor protein ( } \beta \text {-APP)-positive } \\
\text { axons expressed as } \beta \text {-APP-positive axons per square millimeter } \\
\text { per total cross section of the spinal cord in the vehicle-treated } \\
\text { and } \omega \text {-CTX-treated groups. Demyelination was evaluated } \\
\text { semiquantitatively as described in Materials and Methods. } \omega \text { - } \\
\text { CTX-treated animals showed significantly lower degrees of } \\
\text { demyelination. The number of ED1-positive cells and the } \\
\text { number of injured axons were significantly reduced in } \omega \text { - } \\
\text { CTX-treated animals compared with vehicle treatment. } \\
\text { SEM = standard error of the mean. }\end{array}$} \\
\hline
\end{tabular}

treated, $5.1 \pm 1.5$; vehicle treated, $12.5 \pm 1.8 ; p<$ $0.05)$. In the LATE groups ( $\mathrm{n}=4$ each), neurological outcome was not significantly improved after $\omega$-CTX treatment (cumulative score, $7.9 \pm 3.6$ ) compared with vehicle treatment, although two of the four rats did improve. The disease course and the cumulative scores of the different animal groups are given in Figures $7 \mathrm{~J}$ and $\mathrm{K}$.

In general, spinal cord pathology in most of the rats was characterized by perivascular inflammation and demyelination. Inflammatory infiltrates were present around veins and venules, and inflammation was also localized in the meninges with dispersion to the parenchyma adjacent to the pia mater. Inflammation mainly consisted of ED1-positive macrophages and few W3/ 13-positive $\mathrm{T}$ cells.

In accordance with the clinical data, quantitative histopathological examination of the spinal cords demonstrated significantly lower numbers of ED1positive cells in $\omega$-CTX-treated animals around veins and/or in the parenchyma adjacent to the pia mater $(p<0.05$; Table; see Figs 6Q, R) when compared with vehicle-treated rats $(\omega$-CTX-treated and vehicletreated groups were analyzed together). Reduced inflammation was associated with significantly lower demyelination scores compared with the vehicle-treated 
group and restricted to small rims of perivascular demyelination ( $p<0.05$; see the Table, see Fig 6S). Axons immunoreactive for $\beta$-APP were present to a significantly lower degree in $\omega$-CTX-treated animals compared with the vehicle-treated group $(p<0.05$; see the Table, see Fig 6T). In contrast, the vehicletreated group exhibited pronounced perivascular inflammation and abundant inflammation in the parenchyma adjacent to the pia mater (see the Table; see Figs $6 \mathrm{M}, \mathrm{N}$ ) associated with confluent subpial and perivenous demyelination (see the Table; see Fig 6O), and prominent acute axonal injury demonstrated by immunoreactivity for $\beta$-APP (see the Table; see Fig 6P).

\section{Discussion}

In a broader disease context than MS, neuroprotective effects of N-type VDCC antagonists have been described using models of ischemia, brain trauma, and neuropathic pain. ${ }^{33,36,37}$ However, to date, no studies have investigated the effects of N-type VDCC antagonists on neurodegeneration and inflammation under autoimmune conditions. Continuous application of $\omega$-CTX in our study led to axon protection when started before immunization. Although a trend toward a decreased number of degenerating axons was observed on administration of $\omega$-CTX from disease onset, this did not prove to be significant. This is in agreement with our earlier studies, in which application of erythropoietin rescued neurons only if the treatment was given prophylactically ${ }^{11,38}$ and is explained by characteristics of our model, in which neurodegeneration starts before the onset of clinical symptoms. ${ }^{8}$ At the time of disease manifestation, axonal damage within the $\mathrm{ON}$ had progressed ${ }^{6}$ such that therapeutic interventions targeting early pathophysiological events are too late.

The application of $\omega$-CTX in our study not only protected axons that upregulate N-type VDCCs but also reduced demyelination and inflammatory infiltration within the ON. To investigate whether the effect on demyelination is a primary phenomenon resulting from a blockade of N-type VDCCs expressed on oligodendrocytes, we performed costainings of $\mathrm{N}$-type VDCCs and CNPase. Because no oligodendroglial expression of the channels could be detected, this effect might either be secondary to axonal protection or result from the decreased amount of inflammatory infiltration. Because we showed that N-type VDCCs are expressed on macrophages/microglia, it is possible that the decreased demyelination is caused by reduced activation of macrophages/microglia under treatment with $\omega$-CTX. In support of this notion, there is evidence that VDCCs are involved in microglial activation and superoxide anion production. ${ }^{39}$ There is a notable parallel between our results on N-type VDCCs and pre- vious data on other voltage-gated cation channels. Craner and colleagues ${ }^{40}$ and Carrithers and coauthors ${ }^{41}$ showed that sodium channels influence macrophage and microglia activity in neuroinflammatory disorders. Furthermore, it was demonstrated that sodium channel subtypes such as $\mathrm{Na}_{\mathrm{v}} 1.6$ are colocalized with the $\mathrm{Na}^{+} / \mathrm{Ca}^{2+}$ exchanger in degenerating axons in mice with EAE, as well as in acute lesions in patients with MS. ${ }^{42,43}$ Similar to the dual role for N-type VDCCs proposed in our study, Waxman ${ }^{44}$ noted that sodium channels appear to play two parallel roles in neuroinflammatory disease: First, they permit ion fluxes that directly injure axons, and second, they exert immunomodulatory effects. Another similarity between N-type VDCCs and voltage-gated sodium channels is their expression on astrocytes. Sontheimer and coauthors ${ }^{45,46}$ reported that voltage-gated sodium channels are present ${ }^{45}$ and functional ${ }^{46}$ on astrocytes. Whereas, among other functions, sodium channels appear to be important for maintaining the activity of the $\mathrm{Na}^{+} / \mathrm{K}^{+}$ATPase in these nonexcitable cells, ${ }^{46}$ VDCCs in astrocytes may be involved in the release of neurotrophic factors, ionic homeostasis, and glial network signaling. ${ }^{47,48}$

It is possible that the $\mathrm{Mn}^{2+}$ enhancement we detected within inflamed ONs results from an uptake of this ion via axonal N-type VDCCs that are upregulated in degenerating $\mathrm{ON}$ axons. However, it is also possible that the contrast agent is taken up by macrophages/ microglia or astrocytes as our double-labeling studies showed N-type VDCC expression on both ED1-/ EMAP II- and GFAP-positive cells. This hypothesis is supported by studies showing $\mathrm{Mn}^{2+}$ uptake by astrocytes and microglia, and a correlation between hyperintense areas in $\mathrm{Mn}^{2+}$-enhanced MRI and areas of microglial activation. ${ }^{49,50}$

In our study, we found no effect of $\omega$-CTX on RGC survival. This might be explained by a differential expression of VDCCs in the somata and axons of RGCs. Previous studies investigating somatic expression of VDCCs in dorsal root ganglion neurons after sciatic nerve injury showed a reduced expression of the N-type. ${ }^{51}$ Alternatively, the selective axonal protection by $\omega$-CTX could be caused by an independent pathophysiology of neuronal and axonal damage in our model. This hypothesis is supported by earlier observations showing that a proportion of RGCs die because of electrophysiological dysfunction during the induction phase of optic neuritis, independent of morphologically detectable axonal damage. ${ }^{8}$

For the mechanisms that underlie the potential N-type VDCC upregulation observed in demyelinated axons, we propose a scenario that is supported by studies on metabolism and trafficking of $\mathrm{N}$-type VDCCs. ${ }^{52,53}$ In these studies, a large intraneuronal pool of recruitable $\mathrm{N}$-type VDCCs was observed. In our model 
of optic neuritis, we detected a colocalization of $\alpha_{1 \mathrm{~B}}$ and $\beta$-APP. This suggests that disturbances in axonal transport could lead to an accumulation of vesicles containing $\mathrm{N}$-type VDCCs within demyelinating axons and their insertion to the membrane. This mechanism could possibly explain the greater protective effect of $\omega$-CTX that we observed on smaller-diameter, as opposed to larger-diameter, axon fibers. Conceivably, insertion of N-type VDCCs into axonal membranes would result in a larger number of VDCCs per axonal volume in smaller axon fibers, permitting a greater pathological influx of $\mathrm{Ca}^{2+}$ into these smaller axons. This mechanism could also be an explanation for the preferential loss of small-diameter axons observed in MS. ${ }^{21}$ Until this point, the scenario is similar to the one that Kornek and colleagues ${ }^{4}$ proposed. However, considering observations made by Cavalie and colleagues, ${ }^{54}$ who detected enhanced calcium currents in PC12 cells after cotransfection with c-fos and c-jun, an additional mechanism could be taken into account: The expression of high-voltage-activated VDCCs may be induced by immediate early genes at a transcriptional level. Therefore, we postulate that in parallel with the insertion of accumulated vesicles containing $\mathrm{N}$-type VDCCs into the axonal membrane, immediate early genes induce synthesis of N-type VDCCs in neurons under autoimmune inflammatory conditions. Similarly, Craner and coauthors ${ }^{55}$ showed increased sodium channel synthesis in RGC bodies during EAE. However, the question remains whether there is a global upregulation of transcription in autoimmune inflammation, or whether transcription is selectively upregulated for specific proteins. Craner and coauthors ${ }^{55}$ reported not only increased synthesis of $\mathrm{Na}_{\mathrm{v}} 1.2$ but also reduced expression of $\mathrm{Na}_{\mathrm{v}} 1.6$ channels. Therefore, it is more likely that the phenomenon they observed is a switch in gene expression rather than a general upregulation. However, nuclear factor- $\mathrm{\kappa} \mathrm{B}$, a transcription factor of global importance, has recently been linked to the pathophysiology of autoimmune demyelinating central nervous system diseases, ${ }^{56}$ suggesting a way in which an upregulation of transcription might have more general effects.

Further studies are needed to explore the pathophysiological role of other VDCC types or AMPA/kainate receptors, or both, which have been shown to influence EAE, ${ }^{26,57}$ and for which we observed some effect in $\mathrm{Mn}^{2+}$-enhanced MRI.

This work was supported by the 6th Framework Program of the European Union, NeuroproMiSe (LSHM-CT-2005-018637, R.D.), the Medical Faculty of the University of Göttingen (Junior Research Group Program, R.D.), and the Serbian Ministry of Science (143005, I.G.).
We thank N. Meyer and I. Boger for excellent technical support and M. Garrido for helpful comments.

\section{References}

1. Trapp BD, Ransohoff R, Rudick R. Axonal pathology in multiple sclerosis: relationship to neurologic disability. Curr Opin Neurol 1999;12:295-302.

2. Bitsch A, Schuchardt J, Bunkowski S, et al. Acute axonal injury in multiple sclerosis. Correlation with demyelination and inflammation. Brain 2000;123:1174-1183.

3. Losseff NA, Miller DH. Measures of brain and spinal cord atrophy in multiple sclerosis. J Neurol Neurosurg Psychiatry 1998;64:S102-S105.

4. Kornek B, Storch MK, Bauer J, et al. Distribution of a calcium channel subunit in dystrophic axons in multiple sclerosis and experimental autoimmune encephalomyelitis. Brain 2001;124: $1114-1124$.

5. Peterson JW, Bo L, Mork S, et al. Transected neurites, apoptotic neurons, and reduced inflammation in cortical multiple sclerosis lesions. Ann Neurol 2001;50:389-400.

6. Meyer R, Weissert R, Diem R, et al. Acute neuronal apoptosis in a rat model of multiple sclerosis. J Neurosci 2001;21: 6214-6220.

7. Diem R, Hobom M, Maier K, et al. Methylprednisolone increases neuronal apoptosis during autoimmune CNS inflammation by inhibition of an endogenous neuroprotective pathway. J Neurosci 2003;23:6993-7000.

8. Hobom M, Storch MK, Weissert R, et al. Mechanisms and time course of neuronal degeneration in experimental autoimmune encephalomyelitis. Brain Pathol 2004;14:148-157.

9. Hauser SL, Oksenberg JR. The neurobiology of multiple sclerosis: genes, inflammation, and neurodegeneration. Neuron 2006;52:61-76.

10. Wekerle H, Kojima K, Lannes-Vieira J, et al. Animal models. Ann Neurol 1994;36:S47-S53.

11. Diem R, Sättler MB, Merkler D, et al. Combined therapy with methylprednisolone and erythropoietin in a model of multiple sclerosis. Brain 2005;128:375-385.

12. George EB, Glass JD, Griffin JW. Axotomy-induced axonal degeneration is mediated by calcium influx through ion-specific channels. J Neurosci 1995;15:6445-6452.

13. Fern R, Ransom BR, Waxman SG. Voltage-gated calcium channels in CNS white matter: role in anoxic injury. J Neurophysiol 1995;74:369-377.

14. Brown AM, Westenbroek RE, Catterall WA, et al. Axonal L-type Ca2+ channels and anoxic injury in rat CNS white matter. J Neurophysiol 2001;85:900-911.

15. Imaizumi T, Kocsis JD, Waxman SG. The role of voltage-gated $\mathrm{Ca} 2+$ channels in anoxic injury of spinal cord white matter. Brain Res 1999;817:84-92.

16. Stys PK. General mechanisms of axonal damage and its prevention. J Neurol Sci 2005;233:3-13.

17. Eder C. Ion channels in microglia (brain macrophages). Am J Physiol 1998;275:C327-C342.

18. Boucsein C, Kettenmann H, Nolte C. Electrophysiological properties of microglial cells in normal and pathologic rat brain slices. Eur J Neurosci 2000;12:2049-2058.

19. Badou A, Jha MK, Matza D, et al. Critical role for the beta regulatory subunits of Cav channels in T lymphocyte function. Proc Natl Acad Sci USA 2006;103:15529-15534.

20. Weissert R, Wallstrom E, Storch MK, et al. MHC haplotypedependent regulation of MOG-induced EAE in rats. J Clin Invest 1998;102:1265-1273.

21. DeLuca GC, Ebers GC, Esiri MM. Axonal loss in multiple sclerosis: a pathological survey of the corticospinal and sensory tracts. Brain 2004;127:1009-1018. 
22. Storch MK, Stefferl A, Brehm U, et al. Autoimmunity to myelin oligodendrocyte glycoprotein in rats mimics the spectrum of multiple sclerosis pathology. Brain Pathol 1998;8:681-694.

23. Kornek B, Storch MK, Weissert R, et al. Multiple sclerosis and chronic autoimmune encephalomyelitis: a comparative quantitative study of axonal injury in active, inactive, and remyelinated lesions. Am J Pathol 2000;157:267-276.

24. Storch MK, Weissert R, Birnbacher R, et al. MHC gene related effects on microglia and macrophages in experimental autoimmune encephalomyelitis determine the extent of axonal injury. Brain Pathol 2002;12:287-299.

25. Boretius S, Gadjanski I, Demmer I, et al. MRI of optic neuritis in a rat model. Neuroimage 2008;41:323-334.

26. Smith T, Groom A, Zhu B, et al. Autoimmune encephalomyelitis ameliorated by AMPA antagonists. Nat Med 2000;6: 62-66.

27. Turner RJ, Van den Heuvel C, Vink R. Amiloride increases neuronal damage after traumatic brain injury in rats. J Am Coll Nutr 2004;23:534-537.

28. Akerman S, Williamson DJ, Goadsby PJ. Voltage-dependent calcium channels are involved in neurogenic dural vasodilatation via a presynaptic transmitter release mechanism. Br J Pharmacol 2003;140:558-566.

29. Sun BB, Chiu SY. N-type calcium channels and their regulation by GABAB receptors in axons of neonatal rat optic nerve. J Neurosci 1999;19:5185-5194.

30. Furukawa T, Nukada T, Suzuki K, et al. Voltage and pH dependent block of cloned $\mathrm{N}$-type $\mathrm{Ca} 2+$ channels by amlodipine. Br J Pharmacol 1997;121:1136-1140.

31. Xiao WH, Bennett GJ. Synthetic omega-conopeptides applied to the site of nerve injury suppress neuropathic pains in rats. J Pharmacol Exp Ther 1995;274:666-672.

32. Malmberg AB, Yaksh TL. Effect of continuous intrathecal infusion of omega-conopeptides, N-type calcium-channel blockers, on behavior and antinociception in the formalin and hotplate tests in rats. Pain 1995;60:83-90.

33. Bowersox S, Mandema J, Tarczy-Hornoch K, et al. Pharmacokinetics of SNX-111, a selective N-type calcium channel blocker, in rats and cynomolgus monkeys. Drug Metab Dispos 1997;25:379-383.

34. Murray JC, Barnett G, Tas M, et al. Immunohistochemical analysis of endothelial-monocyte-activating polypeptide-II expression in vivo. Am J Pathol 2000;157:2045-2057.

35. Mueller CA, Schluesener HJ, Conrad S, et al. Lesional expression of a proinflammatory and antiangiogenic cytokine EMAP II confined to endothelium and microglia/macrophages during secondary damage following experimental traumatic brain injury. J Neuroimmunol 2003;135:3-9.

36. Valentino K, Newcomb R, Gadbois T, et al. A selective N-type calcium channel antagonist protects against neuronal loss after global cerebral ischemia. Proc Natl Acad Sci USA 1993;90: $7894-7897$.

37. Burns LH, Jin Z, Bowersox SS. The neuroprotective effects of intrathecal administration of the selective $\mathrm{N}$-type calcium channel blocker ziconotide in a rat model of spinal ischemia. J Vasc Surg 1999;30:334-343.

38. Sättler MB, Merkler D, Maier K, et al. Neuroprotective effects and intracellular signaling pathways of erythropoietin in a rat model of multiple sclerosis. Cell Death Differ 2004;11(suppl 2):S181-S192.

39. Colton CA, Jia M, Li MX, et al. K+ modulation of microglial superoxide production: involvement of voltage-gated $\mathrm{Ca} 2+$ channels. Am J Physiol 1994;266:C1650-C1655.
40. Craner MJ, Damarjian TG, Liu S, et al. Sodium channels contribute to microglia/macrophage activation and function in EAE and MS. Glia 2005;49:220-229.

41. Carrithers MD, Sulayman DH, Carrithers LM, et al. Expression of the voltage-gated sodium channel $\mathrm{Na}_{\mathrm{V}} 1.5$ in the macrophage late endosome regulates endosomal acidification. J Immunol 2007; 178:7822-7832.

42. Craner MJ, Hains BC, Lo AC, et al. Co-localization of sodium channel $\mathrm{Na}_{\mathrm{v}} 1.6$ and the sodium-calcium exchanger at sites of axonal injury in the spinal cord in EAE. Brain 2004;127: 294-303.

43. Craner MJ, Newcombe J, Black JA, et al. Molecular changes in neurons in multiple sclerosis: altered axonal expression of $\mathrm{Na}_{\mathrm{v}} 1.2$ and $\mathrm{Na}_{\mathrm{v}} 1.6$ sodium channels and $\mathrm{Na}+/ \mathrm{Ca} 2+$ exchanger. Proc Natl Acad Sci USA 2004;101:8168-8173.

44. Waxman S. Mechanisms of disease: sodium channels and neuroprotection in multiple sclerosis-current status. Nat Clin Pract Neurol 2008;4:159-169.

45. Sontheimer H, Waxman SG. Ion channels in spinal cord astrocytes in vitro. II. Biophysical and pharmacological analysis of two $\mathrm{Na}+$ current types. Neurophysiology 1992;68:1001-1111.

46. Sontheimer H, Fernandez-Marques E, Ullrich N, et al. Astrocyte $\mathrm{Na}+$ channels are required for maintenance of $\mathrm{Na}^{+} / \mathrm{K}^{+}$ATPase activity. J Neurosci 1994;14:2464-2475.

47. Westenbroeck RE, Bausch SB, Lin RCS, et al. Upregulation of L-type $\mathrm{Ca}^{2+}$ channels in reactive astrocytes after brain injury, hypomyelination and ischemia. J Neurosci 1998;18: 2321-2334.

48. D’Ascenzo M, Vairano M, Andreassi C, et al. Electrophysiological and molecular evidence of $\mathrm{L}-\left(\mathrm{Ca}_{\mathrm{v}} 1\right), \mathrm{N}-\left(\mathrm{Ca}_{\mathrm{v}} 2.2\right)$, and $\mathrm{R}-\left(\mathrm{Ca}_{\mathrm{v}} 2.3\right)$ type $\mathrm{Ca}^{2+}$ channels in rat cortical astrocytes. Glia 2004; $45: 354-363$.

49. Alvestad S, Goa PE, Qu H, et al. In vivo mapping of temporospatial changes in manganese enhancement in rat brain during epileptogenesis. NeuroImage 2007;38:57-66.

50. Haapanen A, Ramadan UA, Autti T, et al. In vivo MRI reveals the dynamics of pathological changes in the brains of cathepsin D-deficient mice and correlates changes in manganese-enhanced MRI with microglial activation. Magn Reson Imaging 2007;25: 1024-1031.

51. Baccei ML, Kocsis JD. Voltage-gated calcium currents in axotomized adult rat cutaneous afferent neurons. J Neurophysiol 2000;83:2227-2238.

52. Sher E, Rosa P, Francolini M, et al. Metabolism and trafficking of N-type-operated calcium channels in neurosecretory cells. J Bioenerg Biomembr 1998;30:399-407.

53. Passafaro M, Rosa P, Sala C, et al. N-type Ca2+ channels are present in secretory granules and are transiently translocated to the plasma membrane during regulated exocytosis. J Biol Chem 1996;271:30096-30104.

54. Cavalie A, Berninger, Haas CA, et al. Constitutive upregulation of calcium channel currents in rat phaeochromocytoma cells: role of c-fos and c-jun. J Physiol 1994;479(pt 1):11-27.

55. Craner MJ, Albert CL, Black JA, Waxman SG. Abnormal sodium channel distribution in optic nerve axons in a model of inflammatory demyelination. Brain 2003;126:1552-1561.

56. van Loo G, De Lorenzi R, Schmidt H, et al. Inhibition of transcription factor NF-kappaB in the central nervous system ameliorates autoimmune encephalomyelitis in mice. Nat Immunol 2006;7:954-961.

57. Brand-Schieber E, Werner P. Calcium channel blockers ameliorate disease in a mouse model of multiple sclerosis. Exp Neurol 2004;189:5-9. 